\title{
Microstructures and their lifetimes in acetamide/electrolyte deep eutectics: anion dependence ${ }^{\dagger}$
}

\author{
SUMAN DAS ${ }^{\mathrm{a}}$, BISWAROOP MUKHERJEE ${ }^{\mathrm{b}}$ and RANJIT BISWAS ${ }^{\mathrm{a}, \mathrm{b}, *}$ \\ ${ }^{a}$ Chemical, Biological and Macromolecular Sciences, S. N. Bose National Centre for Basic Sciences, Block-JD, \\ Sector-III, Salt Lake, Kolkata, West Bengal 700 098, India \\ ${ }^{\mathrm{b}}$ Thematic Unit for Excellence-Computational Materials Science, S. N. Bose National Centre for Basic \\ Sciences, Block-JD, Sector-III, Salt Lake, Kolkata, West Bengal 700 098, India \\ E-mail: ranjit@bose.res.in
}

MS received 30 January 2017; revised 11 March 2017; accepted 11 March 2017

\begin{abstract}
Extensive computer simulations with deep eutectics made of acetamide $\left(\mathrm{CH}_{3} \mathrm{CONH}_{2}\right)$ and lithium salts (LiX) have been performed at $303 \mathrm{~K}$ and $350 \mathrm{~K}$ to identify the solution-phase microstructures in these media and investigate the anion dependence of the size and lifetime distributions of these microstructures. In addition, we explore how the added electrolyte interferes with the natural hydrogen bonded (H-bonded) network structure of liquid acetamide. For this purpose several radial distribution functions have been analysed and visualised. The results reveal that amide-amide $\mathrm{H}$-bond interaction decreases significantly upon the addition of electrolyte, and the interactions of $\mathrm{Li}^{+}$and $\mathrm{X}^{-}\left(\mathrm{X}^{-}\right.$being $\mathrm{NO}_{3}^{-}, \mathrm{Br}^{-}$and $\left.\mathrm{ClO}_{4}^{-}\right)$with $\mathrm{CH}_{3} \mathrm{CONH}_{2}$ lead to heterogeneous solution structures. Furthermore, we have obtained the cluster size and lifetime distributions in order to estimate the size of local microstructures and their stability. Both these distributions are analysed by separating the contributions arising from (a) $\mathrm{CH}_{3} \mathrm{CONH}_{2}-\mathrm{CH}_{3} \mathrm{CONH}_{2}$, (b) $\mathrm{Li}^{+}-\mathrm{CH}_{3} \mathrm{CONH}_{2}$ and (c) $\mathrm{Li}^{+}-\mathrm{X}^{-}$ interactions. The size distribution of $\mathrm{Li}^{+}-\mathrm{X}^{-}$clusters is found to be different from those for the other two. Also, the lifetime distributions show a pronounced anion dependence and suggest cluster stability time up to a few nanoseconds.
\end{abstract}

Keywords. Amide deep eutectics; simulations; cluster size and lifetime distributions; anion dependence.

\section{Introduction}

Deep eutectic solvents (DESs), an alternative to room temperature ionic liquids ${ }^{1,2}$ (RTILs), have received a considerable attention recently because of various fundamental and technological importance. ${ }^{3-10}$ DESs are mainly mixtures of hydrogen bond acceptors (HBA), such as, quaternary phosphonium, ammonium salts with hydrogen bond donors (HBD), for example, glycerol, urea, ethylene glycol, etc. ${ }^{6}$ When they are mixed at a particular mole fraction, the mixture produces liquid upon heating at a temperature much lower than their individual melting temperatures. The liquid phase so accessed remains stable in several cases even at temperatures lower than the room temperature. Deep depression of freezing points (of the constituents) via extensive inter-species interactions and gain in entropy (mainly rotational) for being in the molten state are the principal factors that stabilize the liquid phase. Several interesting

\footnotetext{
*For correspondence

$\dagger$ Dedicated to the memory of the late Professor Charusita Chakravarty.
}

properties of DESs like low vapour pressure, high thermal stability, low melting point, non-toxicity, cheaper cost, etc., make them lucrative for various chemical and industrial applications. ${ }^{11-15}$ In chemical industry, they are used as eco-friendly reaction media, catalysts, etc. ${ }^{4,6}$ Also, DESs are finding many novel applications in bio industry such as dissolution of biopolymers, ${ }^{16}$ extraction of aromatic compounds from plants, ${ }^{17}$ extraction of proteins, ${ }^{18}$ etc. However, smarter and more effective applications of these interesting solvent systems demand a thorough knowledge of structure and dynamics because an understanding of medium effects ${ }^{19-21}$ is a prerequisite to liquid solvent engineering for tailoring a reaction.

Several DESs comprised of amides and electrolytes have been investigated of late via time-resolved fluorescence measurements, ${ }^{22-28}$ dielectric relaxation experiments, ${ }^{29}$ optical Kerr effect spectroscopy ${ }^{30}$ and molecular dynamics simulations. ${ }^{22,23,31}$ These studies have reported and explained fractional viscosity dependence of the translational and rotation times for a dissolved solute in these molten mixtures. The orientational 
mechanism of molten acetamide ${ }^{32}$ as well as acetamide in presence of these electrolytes have been analysed via simulations ${ }^{33}$ where prominent signatures of angular jumps have been detected. Also, the orientational timescale and its connection to the hydrogen bond dynamics in ionic amide deep eutectics has been explored just recently. ${ }^{34}$ Therefore, the dynamics of these systems have been studied rather extensively although the structural aspect has remained largely unexplored. The central theme of the present work is to explore the structural complexities of these amide deep eutectics and its anion dependence.

The solvation of $\mathrm{Li}^{+}$in organic medium which directly influences its transport properties has immense industrial importance. ${ }^{35-38} \mathrm{Li}^{+}$batteries with high energy storage capability is often used as attractive power sources. However, use of $\mathrm{Li}^{+}$battery in large scale poses some challenges in automobile industry. The limitation is mainly due to their poor ionic conductivity arising out of strong co-ordination of $\mathrm{Li}^{+}$to the host solvent molecules. Thus, there is a growing need in industry to design suitable solvents to overcome those shortcomings. For rational design, one needs to have the basic understanding of solvation structure and its connection to dynamics. Several transport properties like diffusion, conductance, viscosity, etc. critically depend on solvation structure. Though it is very difficult to achieve molecular level information about structural properties using traditional fluorescence and other collective measurement techniques, molecular dynamics simulations can be helpful in providing molecular insights. Several room temperature ionic liquids (RTILs) have been investigated $^{39-41}$ via simulations in order to examine the local structure formed. It has been found that $\mathrm{Li}^{+}$, on an average, has co-ordination number of 4 . However, the co-ordination number can differ depending upon the nature of the anion/solvent and their conformation. Since the first co-ordination shell of $\mathrm{Li}^{+}$is highly stable, it diffuses along with its first solvation shell as a composite body. Though DESs comprised of amide and electrolyte resemble dipolar RTILs in terms of interactions, the meso-scale organization in DESs and structural effects on transport properties have not been explored from a basic scientific point of view.

In the present study we have carried out all-atom molecular dynamic simulations of amide/electrolyte DESs containing $\mathrm{CH}_{3} \mathrm{CONH}_{2}$ as the amide and three different types of electrolytes namely lithium bromide $(\mathrm{LiBr})$, lithium nitrate $\left(\mathrm{LiNO}_{3}\right)$ and lithium perchlorate $\left(\mathrm{LiClO}_{4}\right)$ at $303 \mathrm{~K}$ and $350 \mathrm{~K}$. First, we have shown how the acetamide structure changes on adding electrolytes and its dependence on ion identity. Then, we have investigated the kind of micro-structures formed in these molten mixtures and the role played by $\mathrm{Li}^{+}$and its counterpart in forming and stabilising the aggregates. These aggregates have been presented visually also for a better understanding. Next, we have analysed the cluster (aggregate) size and lifetime distributions. Similar to the hydrogen bond analysis as performed previously, ${ }^{34}$ both these distributions have been separated for different contributions arising from (a) $\mathrm{CH}_{3} \mathrm{CONH}_{2}-\mathrm{CH}_{3} \mathrm{CONH}_{2}$, (b) $\mathrm{Li}^{+}-\mathrm{CH}_{3} \mathrm{CONH}_{2}$ and (c) $\mathrm{Li}^{+}-\mathrm{X}^{-}$interactions. This separate analysis provides an insight to the microscopic aggregates and its stability depending upon the ion identity.

\section{Simulation details}

All-atom molecular dynamics simulations were carried out with 512 number of molecules with the composition $\left[0.78 \mathrm{CH}_{3}\right.$ $\left.\mathrm{CONH}_{2}+0.22 \mathrm{LiX}\right]$ at two temperatures $303 \mathrm{~K}$ and $350 \mathrm{~K}$ with DL_POLY version $2.20 .{ }^{42}$ Additionally, all-atom simulation was carried with 256 number of acetamide molecules at $368 \mathrm{~K}$ in order to compare structural differences with DESs. As the experimental melting temperature of neat acetamide is around $353 \mathrm{~K},{ }^{43}$ the pure acetamide system was simulated at a higher temperature $(368 \mathrm{~K})$. The potential function used has the following general form:

$$
\begin{aligned}
U(R)= & \sum_{\text {bonds }} K_{r}\left(r-r_{e q}\right)^{2}+\sum_{\text {angles }} K_{\theta}\left(\theta-\theta_{e q}\right)^{2} \\
& +\sum_{\text {dihedrals }} K_{\varphi}(1+\cos [\eta \phi-\gamma]) \\
& +\sum_{i<j}^{\text {atoms }}\left(\frac{A_{i j}}{R_{i j}^{12}}-\frac{B_{i j}}{R_{i j}^{6}}\right)+\sum_{i<j}^{\text {atoms }} \frac{q_{i} q_{j}}{4 \pi \varepsilon_{0} R_{i j}}
\end{aligned}
$$

In Eq. $1, \mathrm{~K}_{\mathrm{r}}$ denotes the bond constant with the equilibrium bond distance $\mathrm{r}_{\mathrm{eq}}, \mathrm{K}_{\theta}$ the angle constant with the equilibrium angle $\theta_{\mathrm{eq}}, \mathbf{K}_{\varphi}$ the dihedral constant with periodicity $n$, dihedral angle $\varphi$ and phase shift $\delta . R_{i j}$ is the distance between $\mathrm{i}$ and $\mathrm{j}$ atoms with partial charges $q_{i}$ and $q_{j}$, respectively. The force field parameters for $\mathrm{CH}_{3} \mathrm{CONH}_{2}$ were taken from the CHARMM ${ }^{44}$ force field and the same for $\mathrm{Li}^{+}, \mathrm{Br}^{-}, \mathrm{NO}_{3}^{-}, \mathrm{ClO}_{4}^{-}$were taken from the existing literature. ${ }^{45-47}$ These force field parameters were used previously to study reorientational dynamics ${ }^{32-34}$ and density relaxation of these DESs. ${ }^{22,23}$ The force field was constructed using DL_FIELD. ${ }^{48}$ The short-range van der Waals interaction was treated with Lennard-Jones potential ${ }^{49}$ and the long-range electrostatic potential was dealt with via Ewald summation technique. ${ }^{49}$

The initial configuration of the simulated mixture was constructed using Packmol ${ }^{50}$ with large simulation box length. Then, each system was equilibrated in NPT ensemble at $1 \mathrm{~atm}$ pressure for $5 \mathrm{~ns}$ to reach the experimental density. ${ }^{22,30}$ The 
simulated densities were found to be in reasonable agreement with the experimental density (Table S2 in Supplementary Information). Nose-Hoover thermostat ${ }^{51}$ and barostat ${ }^{52}$ were used to control the temperature and pressure with time constant of $0.4 \mathrm{ps}$ and $1.0 \mathrm{ps}$, respectively. After a further equilibration of $5 \mathrm{~ns}$ in NVT ensemble with Nose-Hoover thermostat $^{51}$ with time constant of $0.4 \mathrm{ps}$, the production run was carried out for $100 \mathrm{~ns}$ in NVT ensemble with the final configuration. The periodic boundary condition was employed in all the three directions and the equation of motion was integrated with a time step of 0.5 fs using the velocity Verlet algorithm. ${ }^{49}$ The trajectories were saved every 0.1 ps for further analysis. All the snapshots shown in this paper are constructed using VMD. ${ }^{53}$

\section{Results and Discussion}

\subsection{Radial distribution function}

Study of radial distribution function (RDF) gives a molecular insight into the spatial distributions of atoms/ molecules in the mixture. Several studies ${ }^{54-57}$ have revealed that $\mathrm{Li}^{+}$containing electrolytes, when added to a medium, induces heterogeneity in solution structure. The RDF has been calculated with the following equation:

$$
g_{i j}(r)=\frac{1}{\rho N}\left\langle\sum_{i j} \delta\left(r-r_{i j}\right)\right\rangle
$$

where $\mathrm{N}$ is the number of particles in the system, $\rho$ the number density, $i$ and $j$ are two different types of particles and the brackets indicate ensemble average.

Hydrogen bond, one of the most important and widely studied intermolecular interactions, ${ }^{58-63}$ plays a leading role in the structure and dynamics of the amide compounds. Diffraction techniques, ${ }^{64-68}$ both in the solid and gaseous phases, have been applied to study the structure of acetamide. Two different types of crystal structures exists ${ }^{67,68}$ for acetamide, rhombohedral and the orthorhombic arrangements. But in both the structures acetamide molecules are connected through $\mathrm{H}\left(-\mathrm{CONH}_{2}\right) \cdots \mathrm{O}\left(-\mathrm{CONH}_{2}\right)$ interactions. The representative RDF is shown in Figure 1. A snapshot is shown inside the figure which reveals the geometrical position of acetamide molecules engaged in hydrogen bonding interaction. When compared to the RDFs of the DESs at $303 \mathrm{~K}$, the peak height is found to decrease substantially in presence of the electrolyte indicating a collapse in the amide hydrogen bonding network. It should be noted that the comparison is made between molten acetamide simulated at $368 \mathrm{~K}$ and the DESs at $303 \mathrm{~K}$, which further reflects the mitigating effects of electrolyte.

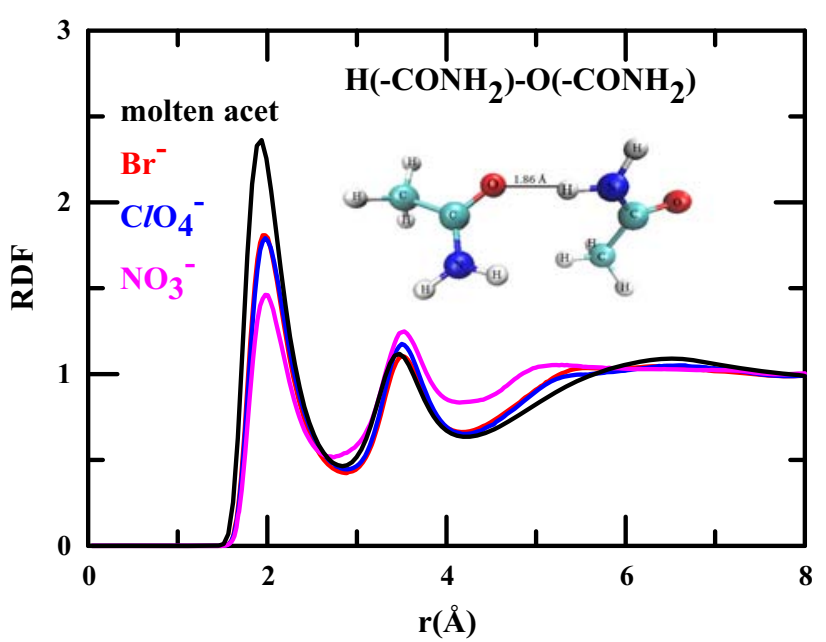

Figure 1. Simulated $\mathrm{RDFs}$ for $\mathrm{H}\left(-\mathrm{CONH}_{2}\right)-\mathrm{O}$ $\left(-\mathrm{CONH}_{2}\right)$ for all DESs at $303 \mathrm{~K}$ and also for molten acetamide at $368 \mathrm{~K}$. Snapshot is provided inside the figure for better understanding.

The length of the $\mathrm{H}\left(-\mathrm{CONH}_{2}\right) \cdots \mathrm{O}\left(-\mathrm{CONH}_{2}\right)$ bond found from the structural investigation of the liquid acetamide is $3.03 \AA^{66,67}$ which matches well with the 1st peak minimum of the RDF. The peak height for the DESs increases as $\mathrm{Br}^{-} \approx \mathrm{ClO}_{4}^{-}>\mathrm{NO}_{3}^{-}$implying that the $\mathrm{H}\left(-\mathrm{CONH}_{2}\right) \cdots \mathrm{O}\left(-\mathrm{CONH}_{2}\right)$ interaction among acetamide molecules is the minimum in presence of $\mathrm{NO}_{3}^{-}$. However, this does not contradict the popular conception of $\mathrm{LiClO}_{4}$ as H-bond breakers. ${ }^{69,70}$ It should be noted that the wavenumber-dependent density relaxations of these DESs suggest that the dynamics of the system is fastest in presence of $\mathrm{ClO}_{4}^{-} \cdot{ }^{22}$ Similar conclusion has also been drawn from the orientaional and $\mathrm{H}$-bond dynamics study of these DESs. ${ }^{34}$

The RDF of $\mathrm{O}\left(-\mathrm{CONH}_{2}\right)-\mathrm{O}\left(-\mathrm{CONH}_{2}\right)$ shown in Figure 2 is quite interesting and it clearly depicts the structural changes of acetamide taking place in the presence of an electrolyte. RDFs presented here indicate that all the main peaks appearing at $\sim 4.9 \AA$ are preceded by a shoulder at $\sim 4 \AA$. The main peak height is highest in molten acetamide and decreases in the presence of electrolyte. Interestingly, all the ionic deep eutectics show an additional peak around $3 \AA$ which is absent in the neat molten acetamide. This closer approach of the $\mathrm{O}\left(-\mathrm{CONH}_{2}\right)$ atoms between acetamide molecules reflects the enhanced interaction in presence of the electrolytes. In order to have the molecular level understanding of the local geometry, we have taken snapshots around the peak positions. The peak at $\sim 5 \AA$ appears when two $\mathrm{O}\left(-\mathrm{CONH}_{2}\right)$ atoms of two different acetamide molecules face each other with one $\mathrm{H}\left(-\mathrm{CONH}_{2}\right)$ atom belonging to one of those acetamide molecules located in between them. 


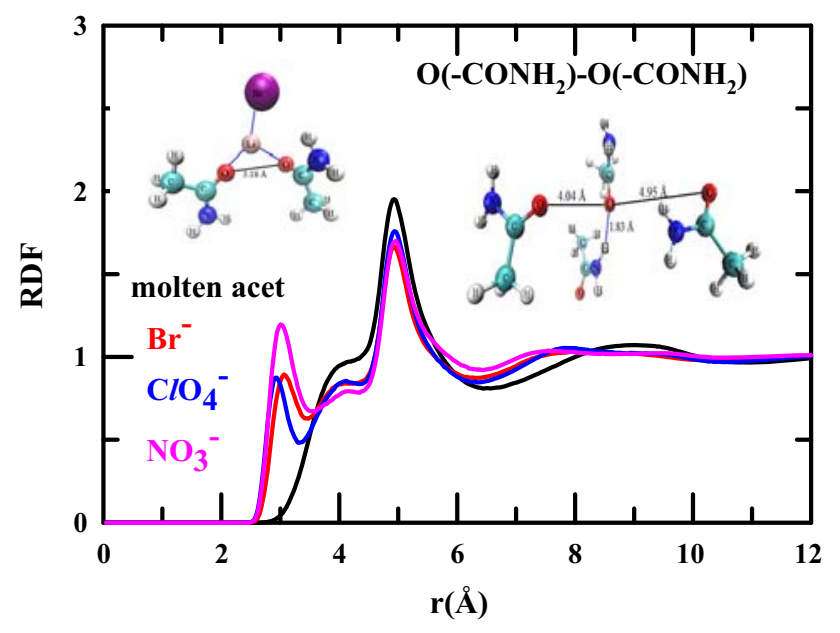

Figure 2. Simulated RDFs for $\mathrm{O}\left(-\mathrm{CONH}_{2}\right)-\mathrm{O}$ $\left(-\mathrm{CONH}_{2}\right)$ for all DESs at $303 \mathrm{~K}$ and also for molten acetamide at $368 \mathrm{~K}$. Various snapshots are provided at different length scales which show the effect of electrolytic interactions.

Interestingly, the distance of $\mathrm{O}\left(-\mathrm{CONH}_{2}\right)$ with this $\mathrm{H}\left(-\mathrm{CONH}_{2}\right)$ is $\sim 1.9 \AA$ which is around the peak position of $\mathrm{O}\left(-\mathrm{CONH}_{2}\right)-\mathrm{H}\left(-\mathrm{CONH}_{2}\right) \mathrm{RDF}$. Therefore, this peak evolves as the main peak as it facilitates the hydrogen bonding interaction between two acetamide molecules and hence the peak order is similar to Figure 1. The shoulder at $\sim 4 \AA$ appears when there is no $\mathrm{H}\left(-\mathrm{CONH}_{2}\right)$ atom in between them. Next, we explain the peak position at $\sim 3 \AA$ which is observed only in the presence of electrolytes. It is evident from the snapshot that the closest approach between two $\mathrm{O}\left(-\mathrm{CONH}_{2}\right)$ atoms is possible when there is one $\mathrm{Li}^{+}$in between them interacting with both the $\mathrm{O}\left(-\mathrm{CONH}_{2}\right)$ atoms. This interaction between $\mathrm{Li}^{+}$and $\mathrm{O}\left(-\mathrm{CONH}_{2}\right)$ is further enhanced when the ions $\left(\mathrm{X}^{-}\right)$attached to $\mathrm{Li}^{+}$interacts with the $\mathrm{H}\left(-\mathrm{CONH}_{2}\right)$ moieties. $\mathrm{NO}_{3}^{-}$, with its three oxygen atoms and planar geometry probably fits as the best candidate and hence exhibits an enhanced peak at this distance as compared to that for the other two ions.

Figure 3 gives RDF for $\mathrm{CH}_{3} \mathrm{CONH}_{2}-\mathrm{CH}_{3} \mathrm{CONH}_{2}$. Note that the $\mathrm{C}\left(-\mathrm{CONH}_{2}\right)$ atom has been considered as the centre of mass of $\mathrm{CH}_{3} \mathrm{CONH}_{2}$ for calculating the $\mathrm{RDF}$. It is interesting to see that the correlation among acetamide molecules extends up to $1.5 \mathrm{~nm}$ which is $\sim 3$ times the diameter of an acetamide molecule. ${ }^{22}$ Note that similar correlation length also has been found for ionic liquids from the analysis of four-point correlation function. ${ }^{71}$ A closer look at the RDFs suggests the presence of three distinct solvation shells; the first of which appears at $\sim 4.6 \AA$, second at $\sim 9 \AA$ and the third at $\sim 13 \AA$. At a distance smaller than $4.6 \AA, \mathrm{Li}^{+}$and its

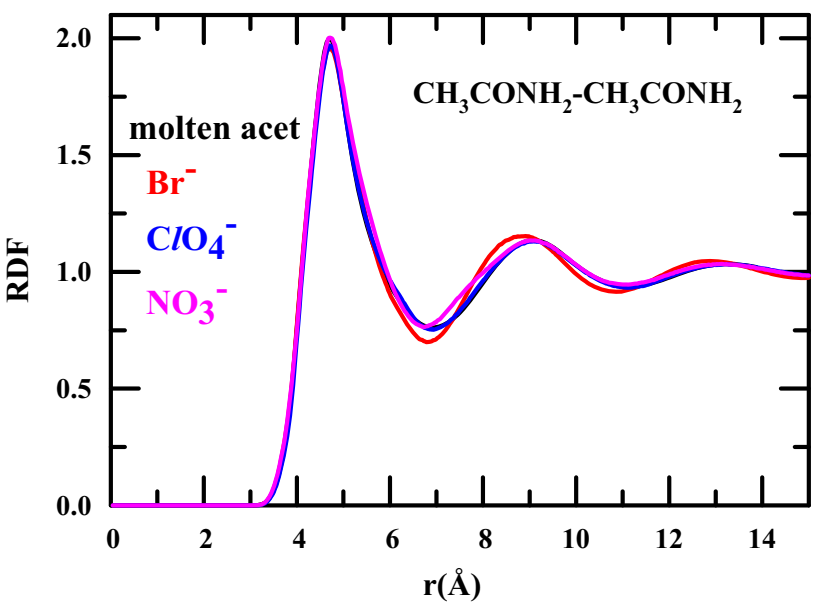

Figure 3. Simulated RDFs for $\mathrm{CH}_{3} \mathrm{CONH}_{2}-\mathrm{CH}_{3} \mathrm{CONH}_{2}$ for all DESs at $303 \mathrm{~K}$ and also for molten acetamide at $368 \mathrm{~K}$.

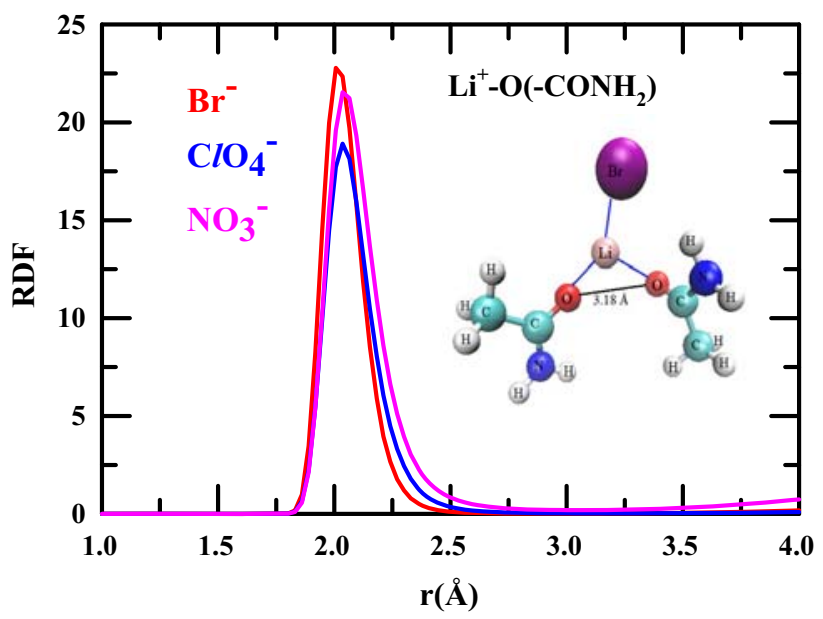

Figure 4. Simulated $\mathrm{RDFs}$ for $\mathrm{Li}^{+}-\mathrm{O}\left(-\mathrm{CONH}_{2}\right)$ for all DESs at $303 \mathrm{~K}$. A snapshot is provided inside the plot.

counter ion are expected to interact with the acetamide molecule.

The strong peak in the RDF of $\mathrm{Li}^{+}-\mathrm{O}\left(-\mathrm{CONH}_{2}\right)$, as observed in Figure 4, indicates that $\mathrm{Li}^{+}$ion is strongly co-ordinated to the $\mathrm{O}\left(-\mathrm{CONH}_{2}\right)$ atom of the amide group to form $\mathrm{Li}^{+}$assisted aggregation of acetamide molecules. This strong interaction with $\mathrm{Li}^{+}$has also been observed for other $\mathrm{Li}^{+}$containing systems. $^{72}$

The $\mathrm{Li}^{+}-\mathrm{Li}^{+}$RDF in Figure 5 is very interesting and provides a rich structural information about these deep eutectics. The $\mathrm{Li}^{+}-\mathrm{Li}^{+}$distance is governed by a variety of factors including the binding with the $\mathrm{O}\left(-\mathrm{CONH}_{2}\right)$ atoms of the acetamide molecules, the conformation of the ions of the electrolytes as the $\mathrm{Li}^{+}$can also bind to them. It is expected that the $\mathrm{Li}^{+}-\mathrm{Li}^{+}$distance would increase if the acetamide molecules can successfully break the strong interaction between $\mathrm{Li}^{+}$and its counter ion. So the nearest peak in Figure 5 comes from the 
$\mathrm{Li}^{+}-\mathrm{O}\left(-\mathrm{CONH}_{2}\right)$ interaction to form the $\mathrm{Li}^{+}$-amide aggregates. And the other peaks originate from the interaction with the ions of the electrolytes. It is likely that if the conformation of the ion is such that $\mathrm{Li}^{+}$can bind with the ion of the electrolyte in more than one way, then the $\mathrm{Li}^{+}-\mathrm{Li}^{+}$distance would vary and, depending on the conformation of the ion of the electrolyte, more than one peak would appear at longer distances. First, we mention the general observations. There are three distinct regions of inhomogeneous distribution as observed from $\mathrm{Li}^{+}-\mathrm{Li}^{+} \mathrm{RDF}$ : (i) at low distances where the RDF is notably structured due to the interaction with $\mathrm{O}\left(-\mathrm{CONH}_{2}\right)$ and ion counterpart, (ii) the missing of a long-range ordering at longer distance, and (iii) an intermediate region where practically the correlation is missing. This very pattern of $\mathrm{Li}^{+}$organization has been observed in various other heterogeneous environments. ${ }^{73,74}$ Now, we would explain the individual characteristics. In presence of $\mathrm{Br}^{-}$, only one peak is observed around $4.3 \AA$ followed by a small shoulder around $5 \AA$. Geometry analysis suggests that this peak arises when a $\mathrm{Br}^{-}$sits in between two $\mathrm{Li}^{+}$. A broad second peak also appears at a larger distance around $8 \AA$. Note this second peak position follows the size of the ion: $\mathrm{NO}_{3}^{-}>\mathrm{Br}^{-}>\mathrm{ClO}_{4}^{-}$.

In presence of $\mathrm{NO}_{3}^{-}$, the first peak appears at $\sim 2.8 \AA$ and is bifurcated in nature. The second peak develops at longer distances, $\sim 4.25 \AA$ followed by another small peak at $\sim 5.0 \AA$. We have captured snapshots at these various distances in order to understand the local geometry. The first peak appears when both $\mathrm{Li}^{+}$interact simultaneously with multiple $\mathrm{NO}_{3}^{-}$and $\mathrm{CH}_{3} \mathrm{CONH}_{2}$ molecules forming complex aggregates. A slight change in the local geometry to avail the multiple co-ordination sites results in the bifurcation as observed in the RDF. Note that this peak is observed only in presence of $\mathrm{NO}_{3}^{-}$ due to the following reasons: (i) $\mathrm{NO}_{3}^{-}$has the smallest size among the ions. So it can fit easily inside the

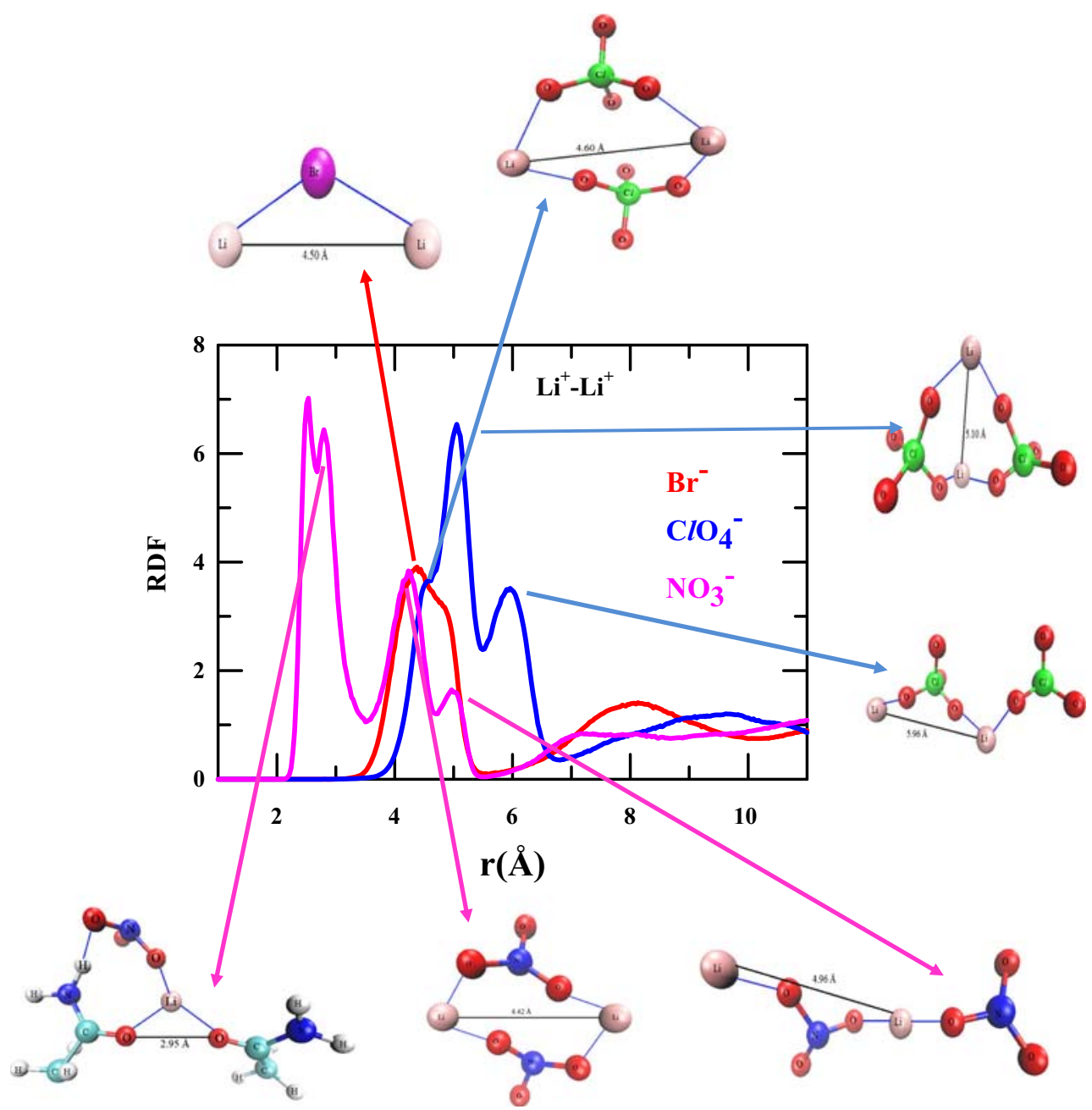

Figure 5. Simulated RDFs for $\mathrm{Li}^{+}-\mathrm{Li}^{+}$for all DESs at $303 \mathrm{~K}$. Various snapshots at different length scales are provided inside the figure that clearly manifest the possible interactions depending on the nature of the anion. Details are discussed in the main text. 


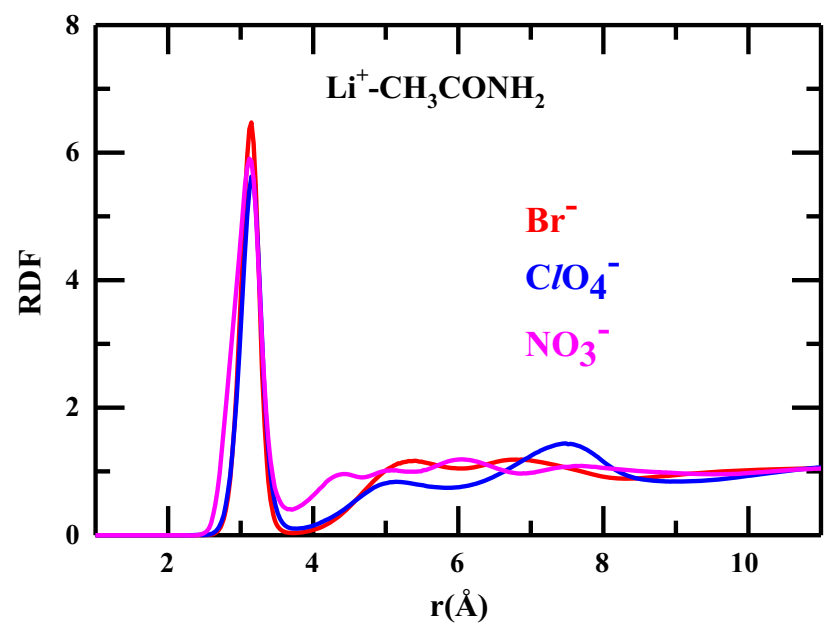

Figure 6. Simulated RDFs for $\mathrm{Li}^{+}-\mathrm{CH}_{3} \mathrm{CONH}_{2}$ for all DESs at $303 \mathrm{~K}$.

cavity and (ii) $\mathrm{NO}_{3}^{-}$, being planar, its three $\mathrm{O}\left(-\mathrm{NO}_{3}^{-}\right)$ atoms can provide a degeneracy for interaction with $\mathrm{H}\left(-\mathrm{CONH}_{2}\right)$ atoms of acetamide molecules, generating an extra stabilization to the resulting complex as compared to the other ions. The other two peaks arise due to various anion conformations. The peak at $\sim 4.3 \AA$ arises when both $\mathrm{Li}^{+}$interacts with two $\mathrm{NO}_{3}^{-}$to form an eight member closed ring. The next peak at $\sim 5 \AA$ arises when both $\mathrm{Li}^{+}$interact with $\mathrm{NO}_{3}^{-}$to form a linear chain-like structure. These different structures reflect complexity inherent to this particular DES. Similar trend is also observed for $\mathrm{ClO}_{4}^{-}$containing system. Note, multiple peaks are not observed in presence of $\mathrm{Br}^{-}$as the multiple anion conformation is not possible here.

Figure 6 shows the $\mathrm{RDF}$ of $\mathrm{Li}^{+}$with $\mathrm{CH}_{3} \mathrm{CONH}_{2}$. The interaction between $\mathrm{Li}^{+}$and $\mathrm{CH}_{3} \mathrm{CONH}_{2}$ is quite strong as evident from the peak height mainly due to the strong electrostatic interaction with $\mathrm{O}\left(-\mathrm{CONH}_{2}\right)$. Hence, the ordering of the peak height follows the ordering of the RDF between $\mathrm{Li}^{+}$and $\mathrm{O}\left(-\mathrm{CONH}_{2}\right)$. Next, we discuss the $\mathrm{RDF}$ between $\mathrm{X}^{-}$and $\mathrm{CH}_{3} \mathrm{CONH}_{2}$ shown in Figure 7 . Here also the closest approach is possible in case of $\mathrm{NO}_{3}^{-}$with smallest size giving rise to the peak at the smallest length scale. Note that similar to the $\mathrm{Li}^{+}-\mathrm{Li}^{+}$ $\mathrm{RDF}$, the RDFs here are also bifurcated in presence of $\mathrm{NO}_{3}^{-}$and $\mathrm{ClO}_{4}^{-}$due to different ion conformations. It should be mentioned that the $\mathrm{RDF}$ between $\mathrm{Li}^{+}$and $\mathrm{CH}_{3} \mathrm{CONH}_{2}$ produces the peak at $\sim 3 \AA$, and then at $\sim 4 \AA$ the RDF between $\mathrm{X}^{-}$and $\mathrm{CH}_{3} \mathrm{CONH}_{2}$ picks up. At a slightly longer distance at $\sim 5 \AA$ the principal peak of $\mathrm{CH}_{3} \mathrm{CONH}_{2}-\mathrm{CH}_{3} \mathrm{CONH}_{2} \mathrm{RDF}$ grows. The picture that may be surmised is that $\mathrm{Li}^{+}$interacts strongly with $\mathrm{X}^{-}$to form a complex and this complex is solvated by the

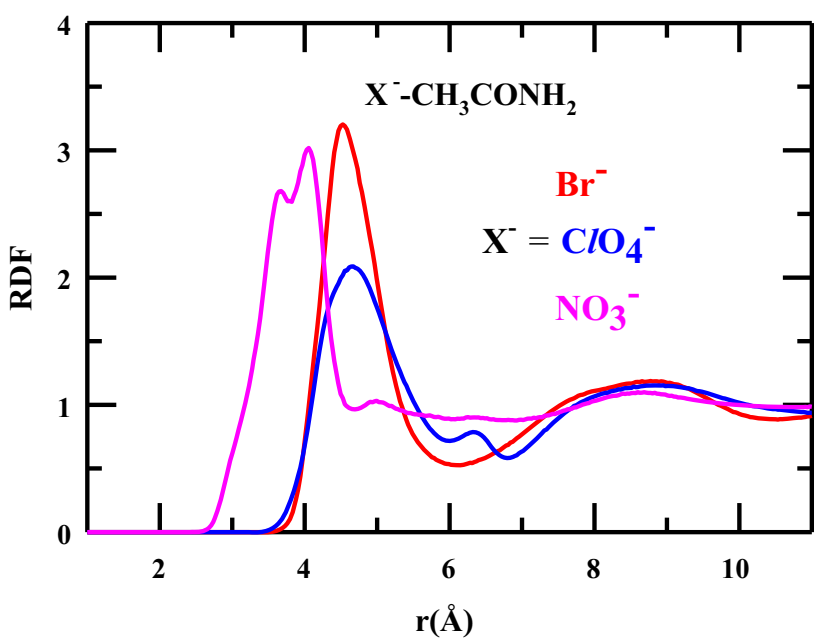

Figure 7. Simulated $\mathrm{RDFs}$ for $\mathrm{X}^{-}-\mathrm{CH}_{3} \mathrm{CONH}_{2}$ for all DESs at $303 \mathrm{~K}$. Here, $\mathrm{X}^{-}$represents various anions $\left(\mathrm{Br}^{-}, \mathrm{ClO}_{4}^{-}\right.$and $\left.\mathrm{NO}_{3}^{-}\right)$.

surrounding acetamide molecules. This renders inhomogeneity in the solution structure in these ionic deep eutectics.

\subsection{Cluster size and lifetime analysis}

It is clear from the RDF analyses that different kinds of clusters/aggregates are formed in these ionic deep eutectics which give rise to complex solution structures. Here, we have separated three different types of clusters: (a) $\mathrm{CH}_{3} \mathrm{CONH}_{2}-\mathrm{CH}_{3} \mathrm{CONH}_{2}$, (b) $\mathrm{Li}^{+}-\mathrm{CH}_{3} \mathrm{CONH}_{2}$ and (c) $\mathrm{Li}^{+}-\mathrm{X}^{-}$. The clusters have been defined based on the corresponding RDFs. Specifically, $\mathrm{CH}_{3} \mathrm{CONH}_{2}$ molecules are assigned in the same cluster if the centre of mass distance between two $\mathrm{CH}_{3} \mathrm{CONH}_{2}$ molecules is less than or equal to the first minimum following the first peak of the $\mathrm{CH}_{3} \mathrm{CONH}_{2}-\mathrm{CH}_{3} \mathrm{CONH}_{2} \mathrm{RDF}$ ( $7 \AA$ for all the ions). Note, $\mathrm{CH}_{3} \mathrm{CONH}_{2}$ molecules are connected via a hydrogen bond network joining $\mathrm{O}\left(-\mathrm{CONH}_{2}\right)$ atom of one $\mathrm{CH}_{3} \mathrm{CONH}_{2}$ and $\mathrm{H}\left(-\mathrm{CONH}_{2}\right)$ of the other. This $\mathrm{H}$-bond between two $\mathrm{CH}_{3} \mathrm{CONH}_{2}$ molecules has been defined previously ${ }^{32,33}$ based on the well-accepted distance (R) and angle criteria (deg) and validity of the definition also has been justified successfully. Two $\mathrm{CH}_{3} \mathrm{CONH}_{2}$ molecules are considered to be H-bonded if (i) the distance between the oxygen and the nitrogen atoms of two different $\mathrm{CH}_{3} \mathrm{CONH}_{2}$ molecules, $R_{O N}$, is less than the first minimum of the corresponding RDF $\left(R_{\text {cut-off }}\right)$, and (ii) the angle between the vector joining nitrogen and amide hydrogen atom of one $\mathrm{CH}_{3} \mathrm{CONH}_{2}$ molecule and the vector joining this nitrogen atom and oxygen atom of the other $\mathrm{CH}_{3} \mathrm{CONH}_{2}$ molecule, $\theta_{\mathrm{ONH}}$ is less than $30^{\circ}$. For all the ions at both the temperatures, $R_{\text {cut-off }}$ is found to be $4 \AA$. Since the criterion we have 


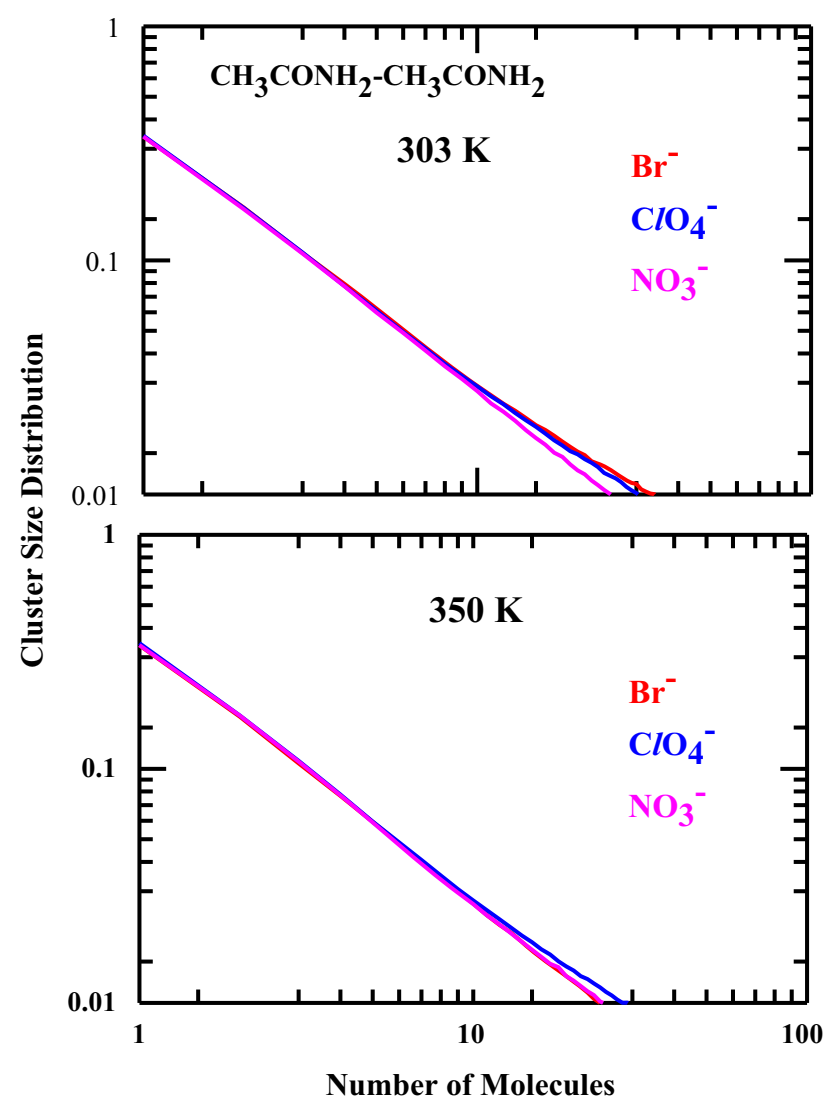

Figure 8. Anion dependence of cluster size distributions of $\mathrm{CH}_{3} \mathrm{CONH}_{2}-\mathrm{CH}_{3} \mathrm{CONH}_{2}$ for all DESs. The upper panel shows the distribution at $303 \mathrm{~K}$ and the lower panel shows the same at $350 \mathrm{~K}$.

employed here does not include any of these, we have checked the validity of our cluster definition. First, we selected pairs of $\mathrm{CH}_{3} \mathrm{CONH}_{2}$ molecules whose centre of mass distance is less than $7 \AA$. Then, we calculated the distribution of $R_{O N}$ and $\theta_{\mathrm{ONH}}$ for these selected pair of molecules. The ion dependence of this distance and angle probability distribution at $303 \mathrm{~K}$ is provided in Figure S3 (Supplementary Information). It is evident from the plot that the selected pairs of $\mathrm{CH}_{3} \mathrm{CONH}_{2}$ molecules also include pairs of $\mathrm{CH}_{3} \mathrm{CONH}_{2}$ molecules which are hydrogen bonded. So, we continue to use this definition to calculate cluster size distribution among acetamide molecules. Similarly, for defining a cluster between $\mathrm{Li}^{+}-\mathrm{CH}_{3} \mathrm{CONH}_{2}$ and $\mathrm{Li}^{+}-\mathrm{X}^{-}$pairs, the cut-off distance has been selected based on the first minimum of the corresponding RDFs. This distance is $3.8 \AA$ for $\mathrm{Li}^{+}-\mathrm{CH}_{3} \mathrm{CONH}_{2}$ pairs. For $\mathrm{Li}^{+}-\mathrm{X}^{-}$clusters, the cut-off distance is $3.2 \AA, 4.0 \AA$ and $3.2 \AA$ for $\mathrm{Br}^{-}, \mathrm{ClO}_{4}^{-}$and $\mathrm{NO}_{3}^{-}$, respectively. Note that similar cluster definition has been used previously for other systems also. ${ }^{75,76}$

Figure 8 shows the anion dependence of the size distribution for $\mathrm{CH}_{3} \mathrm{CONH}_{2}-\mathrm{CH}_{3} \mathrm{CONH}_{2}$ clusters. The

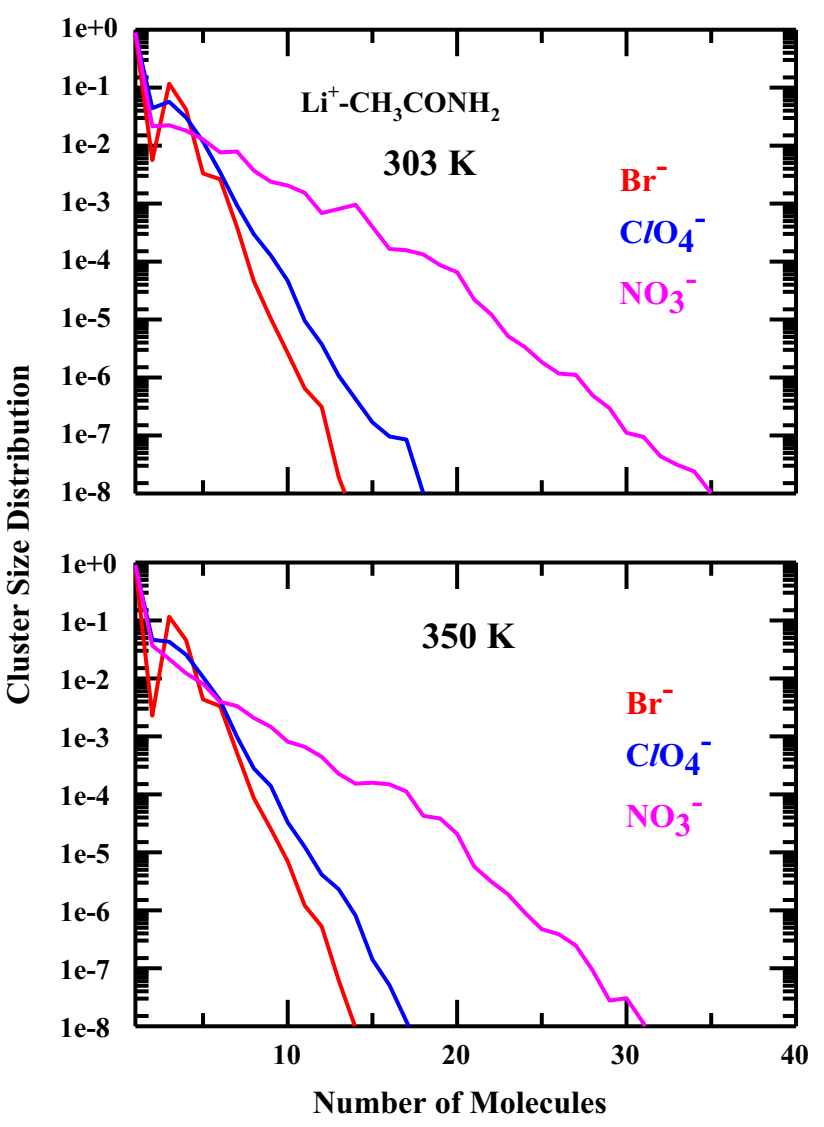

Figure 9. Anion dependence of cluster size distributions of $\mathrm{Li}^{+}-\mathrm{CH}_{3} \mathrm{CONH}_{2}$ for all DESs. The upper panel shows the distribution at $303 \mathrm{~K}$ and the lower panel shows the same at $350 \mathrm{~K}$.

upper panel shows the distribution at $303 \mathrm{~K}$ and the lower panel shows the same at $350 \mathrm{~K}$. Note, the cluster size distribution has been calculated as a fraction of the total number of clusters; that is, if the number of cluster of size $\mathrm{i}$ is $P(i)$ then the total number of clusters is $P=\sum_{i} P(i)$. Subsequently, the comparison has been made between the cluster of size 1 , that is, not bonded to any other neighbour and cluster of larger size. It is evident from Figure 8 that $\mathrm{CH}_{3} \mathrm{CONH}_{2}-\mathrm{CH}_{3} \mathrm{CONH}_{2}$ cluster size distribution does not depend either on the ion identity or the temperature. The distribution extends up to $\sim 25-30 \mathrm{CH}_{3} \mathrm{CONH}_{2}$ molecules or $\sim 100-120 \AA$ (considering the diameter of $\mathrm{CH}_{3} \mathrm{CONH}_{2} \sim 4 \AA$ ). ${ }^{25} \mathrm{How}$ ever, beyond $6 \mathrm{CH}_{3} \mathrm{CONH}_{2}$ molecules the probability is found to be even less than $20 \%$. Also, approximately $33 \% \mathrm{CH}_{3} \mathrm{CONH}_{2}$ molecules do not form any cluster with the neighbours. This indicates a substantial breakdown of the $\mathrm{H}$-bond network among $\mathrm{CH}_{3} \mathrm{CONH}_{2}$ molecules in presence of electrolytes.

Next, we discuss the cluster size distribution of $\mathrm{Li}^{+}-\mathrm{CH}_{3} \mathrm{CONH}_{2}$. Figure 9 shows the distribution at both the temperatures. The similar ion dependence is evident from both the plots. It appears that in presence 

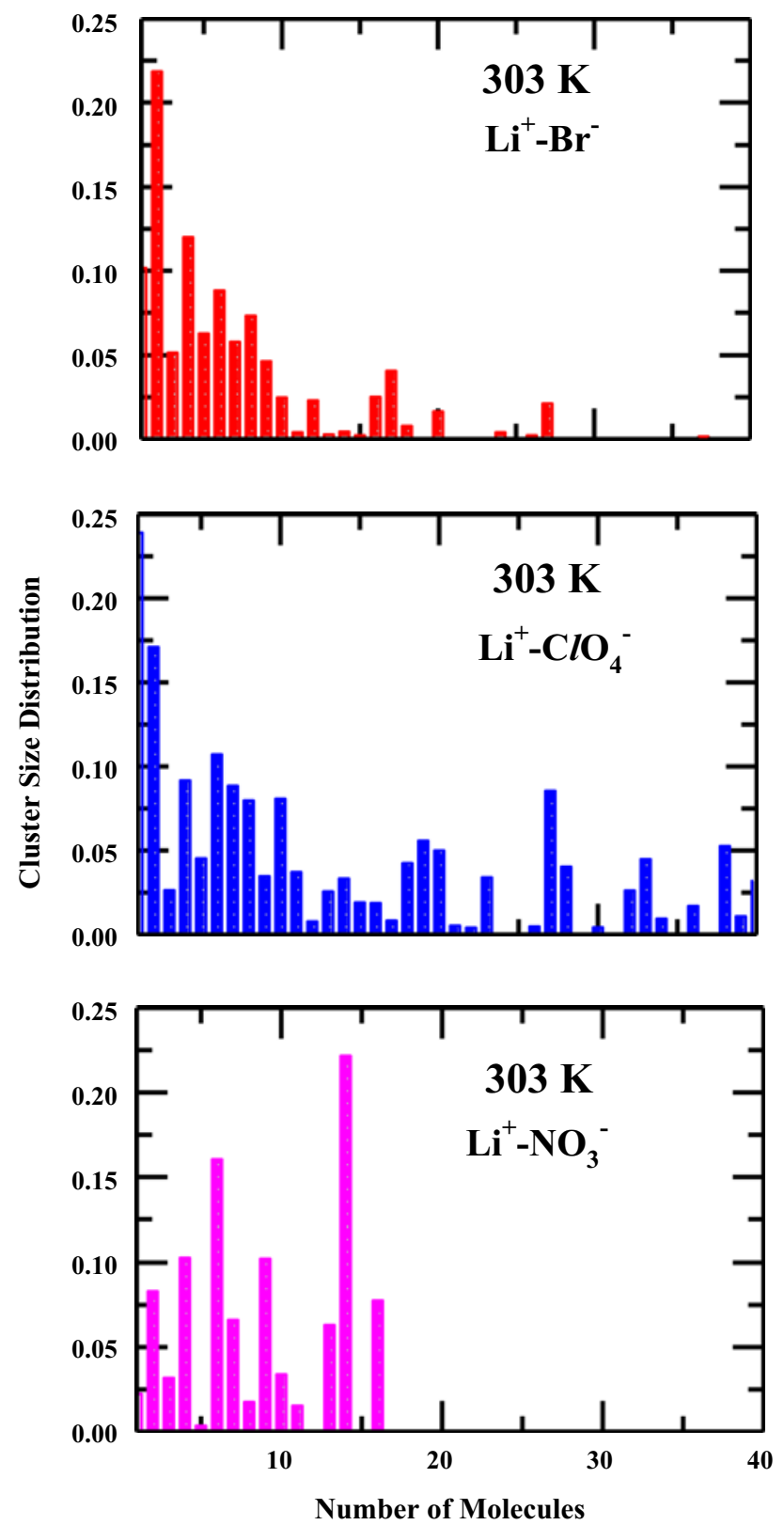

Figure 10. Anion dependence of cluster size distributions of $\mathrm{Li}^{+}-\mathrm{X}^{-}$for all DESs at $303 \mathrm{~K}$. Here, $\mathrm{X}^{-}$represents various anions $\left(\mathrm{Br}^{-}, \mathrm{ClO}_{4}^{-}\right.$and $\left.\mathrm{NO}_{3}^{-}\right)$.

of $\mathrm{NO}_{3}^{-}$maximum clustering is achieved as compared to the other two ions. In presence of $\mathrm{NO}_{3}^{-}$, the cluster size extends up to 35 number of molecules followed by $\mathrm{ClO}_{4}^{-}$and $\mathrm{Br}^{-}$. With increase in temperature, the clustering ability decreases only slightly for all the ions. Figure 10 shows the cluster size distribution of $\mathrm{Li}^{+}-\mathrm{X}^{-}$at $303 \mathrm{~K}$ for all DESs and Figure 11 depicts the same at $350 \mathrm{~K}$. The distribution in this case is slightly different as compared to the other two. For $\mathrm{CH}_{3} \mathrm{CONH}_{2}-\mathrm{CH}_{3} \mathrm{CONH}_{2}$ and $\mathrm{Li}^{+}-\mathrm{CH}_{3} \mathrm{CONH}_{2}$ cluster size distributions, the probability is found to decrease as the number of molecule increases. However, here the
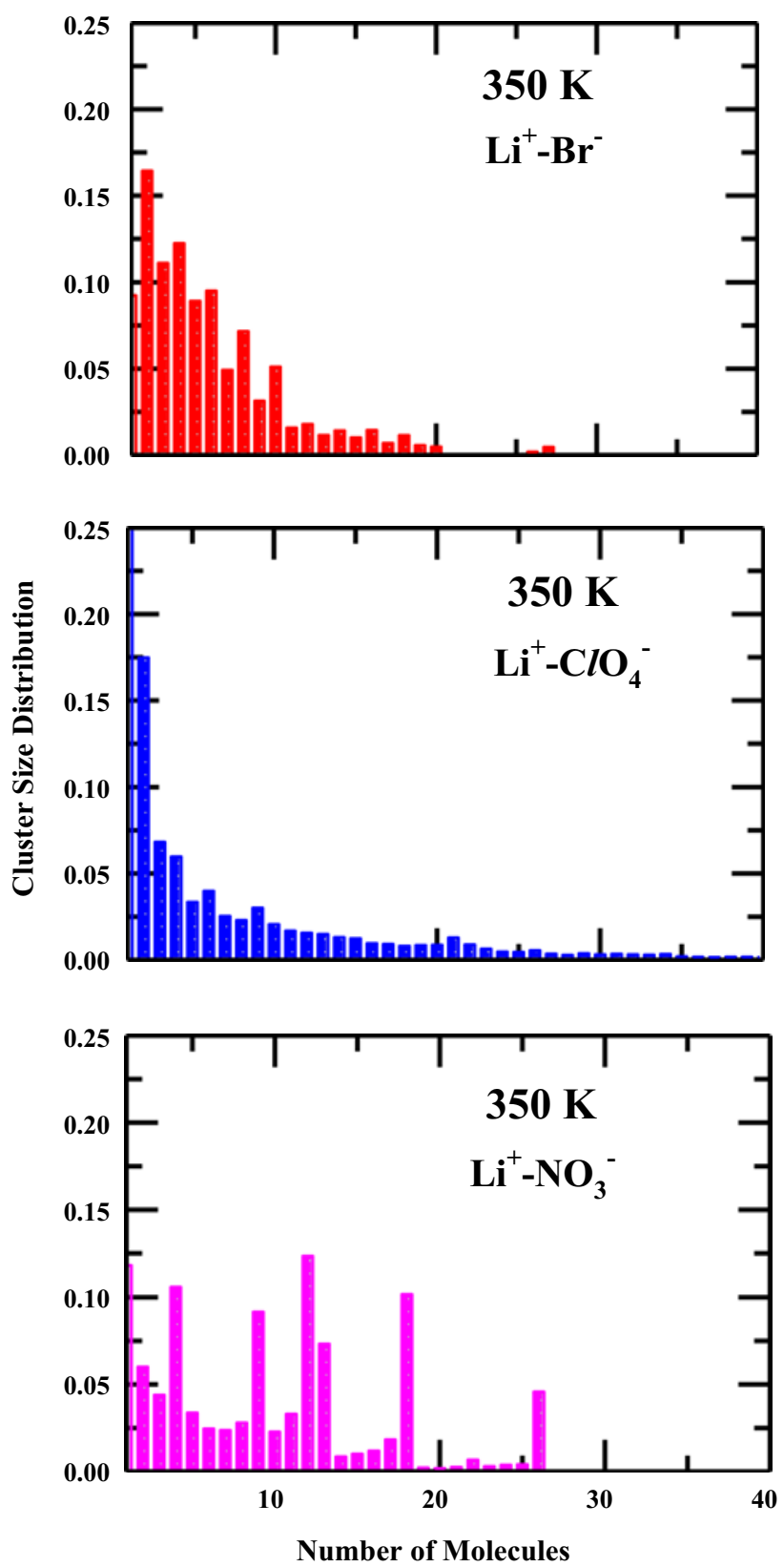

Figure 11. Anion dependence of cluster size distributions of $\mathrm{Li}^{+}-\mathrm{X}^{-}$for all DESs at $350 \mathrm{~K}$. Here, $\mathrm{X}^{-}$represents various anions $\left(\mathrm{Br}^{-}, \mathrm{ClO}_{4}^{-}\right.$and $\left.\mathrm{NO}_{3}^{-}\right)$.

distribution is random for all the ions and show significant ion dependence. For example, in presence of $\mathrm{Br}^{-}$ the distribution stretches up to 25 numbers of molecules but the distribution broadens in presence of $\mathrm{ClO}_{4}^{-}$. Even after 35 numbers of molecules, the distribution does not decay completely. This shows significant presence of $\mathrm{Li}^{+}-\mathrm{ClO}_{4}^{-}$clusters in the mixture. However, in presence of $\mathrm{NO}_{3}^{-}$, the cluster size distribution ceases completely after 15 numbers of molecules. At the elevated temperature, we find that the distribution is somewhat regular for $\mathrm{Br}^{-}$and $\mathrm{ClO}_{4}^{-}$though significant percentage of large clusters exists for both of them. 

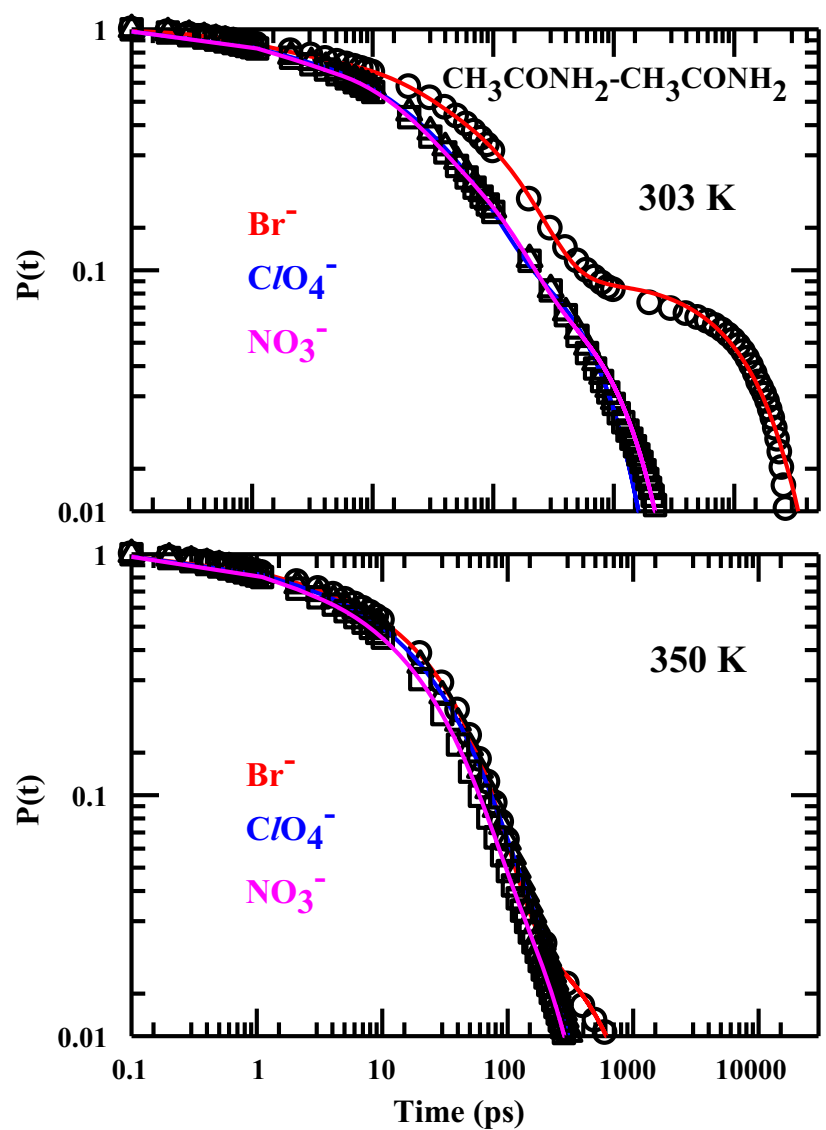

Figure 12. Anion dependence of simulated cluster lifetime distributions, $P(t)$ of $\mathrm{CH}_{3} \mathrm{CONH}_{2}-\mathrm{CH}_{3} \mathrm{CONH}_{2}$ for all DESs. The upper panel shows the distributions at $303 \mathrm{~K}$ and the lower panel shows the same at $350 \mathrm{~K}$.

Now, we present results on cluster lifetime distributions. We have calculated cluster lifetime distributions for $\mathrm{CH}_{3} \mathrm{CONH}_{2}-\mathrm{CH}_{3} \mathrm{CONH}_{2}, \mathrm{Li}^{+}-\mathrm{CH}_{3} \mathrm{CONH}_{2}$ and $\mathrm{Li}^{+}-\mathrm{X}^{-}$clusters at both the temperatures. The procedure we have employed here to calculate the lifetime distribution is similar to the hydrogen bond lifetime $S_{H B}(t) .{ }^{77-79}$ The lifetime can be defined as:

$$
P(t)=\langle h(0) H(t)\rangle /\langle h\rangle
$$

$h\left(t^{\prime}\right)$ is a time dependent variable for a pair of $\mathrm{CH}_{3}$ $\mathrm{CONH}_{2}$ molecules. If the centre of mass distance between two $\mathrm{CH}_{3} \mathrm{CONH}_{2}$ molecules is less than or equal to the cut-off distance, then $h\left(t^{\prime}\right)=1$ or zero otherwise. $H(t)$ is a history dependent function and $H(t)=1$ if $h\left(t^{\prime}\right)$ is unity up to time $t$ from any arbitrary time origin else zero. So, $P(t)$ describes the probability that two $\mathrm{CH}_{3} \mathrm{CONH}_{2}$ molecules remain continuously hydrogen bonded for time $t$. So, the average relaxation time can be treated as the average lifetime of the $\mathrm{CH}_{3} \mathrm{CONH}_{2}$ clusters. Similarly, one can also define cluster lifetime for $\mathrm{Li}^{+}-\mathrm{CH}_{3} \mathrm{CONH}_{2}$ and $\mathrm{Li}^{+}-\mathrm{X}^{-}$clusters.

Figure 12 shows the anion dependence of probability distribution for $\mathrm{CH}_{3} \mathrm{CONH}_{2}-\mathrm{CH}_{3} \mathrm{CONH}_{2}$ clusters.
Table 1. Average lifetime $(\langle\tau\rangle)$ of various types of clusters obtained from the fitting of corresponding lifetime distributions.

\begin{tabular}{lcccc}
\hline Ion & $T(K)$ & $\begin{array}{l}\text { Acet-Acet } \\
(\mathrm{ps})\end{array}$ & $\begin{array}{l}\mathrm{Li}-\text { Acet } \\
(\mathrm{ps})\end{array}$ & $\mathrm{Li}-\mathrm{X}(\mathrm{ps})$ \\
\hline $\mathrm{Br}^{-}$ & 303 & 1595 & 909 & 1067 \\
& 350 & 40 & 123 & 58 \\
$\mathrm{ClO}_{4}^{-}$ & 303 & 106 & 500 & 357 \\
& 350 & 30 & 66 & 72 \\
$\mathrm{NO}_{3}^{-}$ & 303 & 124 & 233 & 4525 \\
& 350 & 25 & 76 & 891 \\
\hline
\end{tabular}

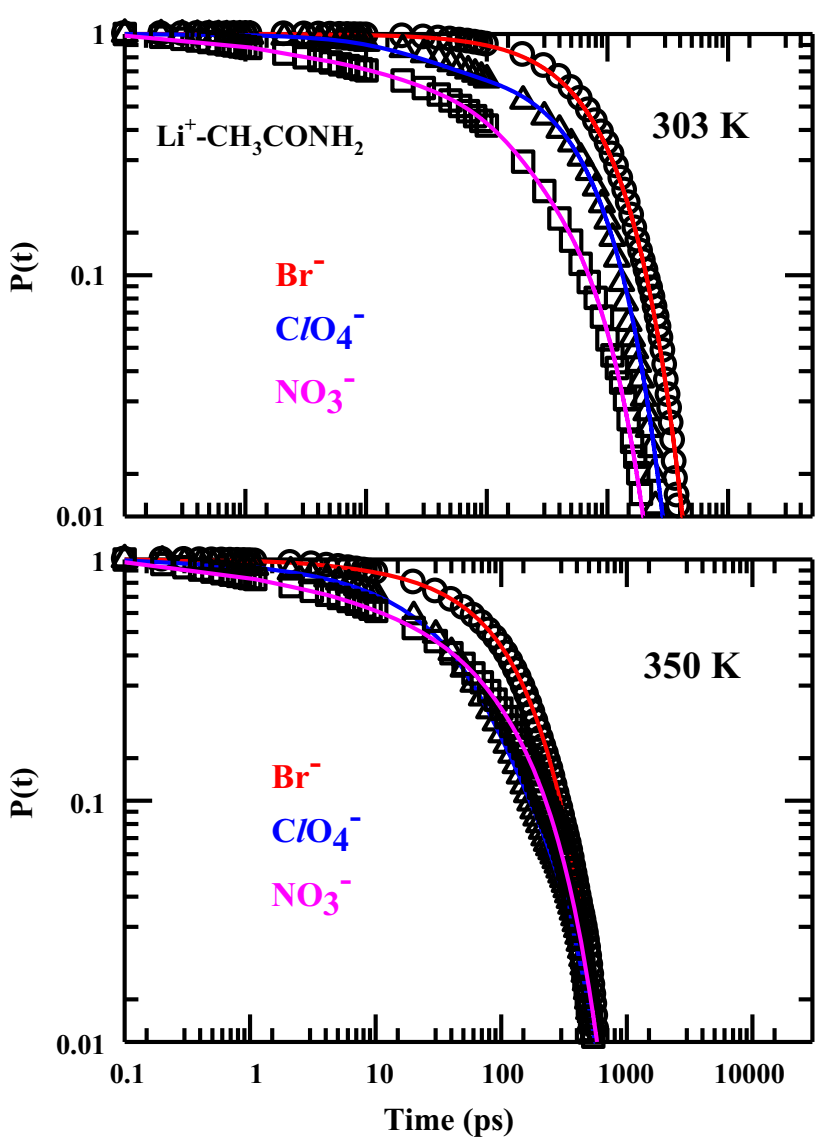

Figure 13. Anion dependence of simulated cluster lifetime distributions, $P(t)$ of $\mathrm{Li}^{+}-\mathrm{CH}_{3} \mathrm{CONH}_{2}$ for all DESs. The upper panel shows the distributions at $303 \mathrm{~K}$ and the lower panel shows the same at $350 \mathrm{~K}$.

The upper panel shows the probability at $303 \mathrm{~K}$ and the lower panel shows the same at $350 \mathrm{~K}$. The dependence on ion identity is prominent at the lower temperature. The probability distributions have been fitted with multiexponential functions which produce timescales ranging from picoseconds to nanoseconds. The average lifetimes are provided in Table 1 and the fitting parameters are provide in Table $\mathrm{S} 4$ in the Supplementary Information. $\mathrm{CH}_{3} \mathrm{CONH}_{2}-\mathrm{CH}_{3} \mathrm{CONH}_{2}$ clusters survive longer in presence of $\mathrm{Br}^{-}$as compared to $\mathrm{NO}_{3}^{-}$and $\mathrm{ClO}_{4}^{-}$. In 

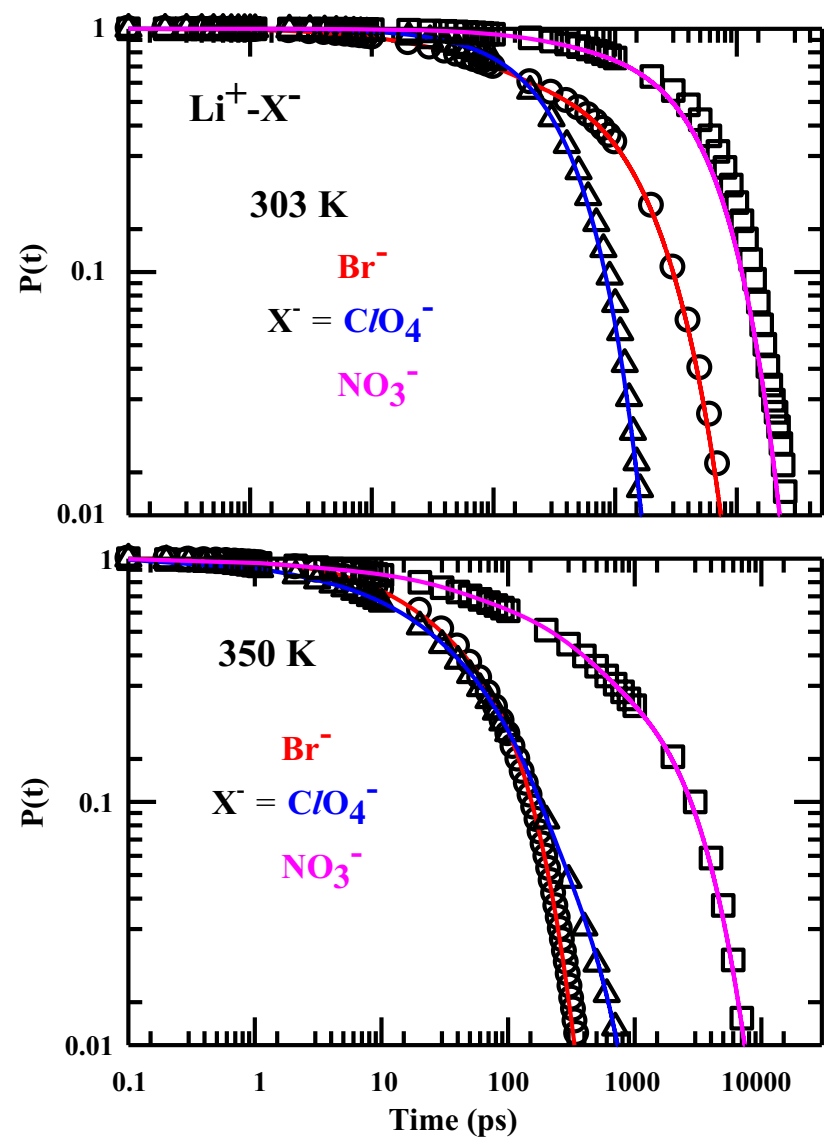

Figure 14. Anion dependence of simulated cluster lifetime distributions, $P(t)$ of $\mathrm{Li}^{+}-\mathrm{X}^{-}\left(X^{-}=\mathrm{Br}^{-}, \mathrm{ClO}_{4}^{-}, \mathrm{NO}_{3}^{-}\right)$for all DESs. The upper panel shows the distributions at $303 \mathrm{~K}$ and the lower panel shows the same at $350 \mathrm{~K}$.

fact, the average lifetime is $\sim 15$ times higher in presence of $\mathrm{Br}^{-}$. The longest time constant found is $\sim 15 \mathrm{~ns}$ which signify the presence of slow dynamics. When the temperature is increased to $350 \mathrm{~K}$, the average lifetime decreases to $\sim 30 \mathrm{ps}$, although a nanosecond component still remains for all the ions. Figure 13 shows the lifetime distributions for $\mathrm{Li}^{+}-\mathrm{CH}_{3} \mathrm{CONH}_{2}$ clusters at both the temperatures. Here also, the cluster survives longer in presence of $\mathrm{Br}^{-}$as compared to the other two ions. Figure 14 gives the lifetime distribution for $\mathrm{Li}^{+}-\mathrm{X}^{-}$ clusters. Here, the average lifetime is the highest in presence of $\mathrm{NO}_{3}^{-}$followed by $\mathrm{Br}^{-}$and $\mathrm{ClO}_{4}^{-}$. The average lifetime is $\sim 4.5 \mathrm{~ns}$ at $303 \mathrm{~K}$ and $\sim 1 \mathrm{~ns}$ at $350 \mathrm{~K}$ for $\mathrm{NO}_{3}^{-}$. This signifies the strength of the $\mathrm{Li}^{+}-\mathrm{NO}_{3}^{-}$clusters which results from favourable planar arrangement of $\mathrm{NO}_{3}^{-}$interacting with $\mathrm{Li}^{+}$, as discussed before. The average lifetime for all the three different types of clusters does not follow any regular pattern which again highlights the inherent complexity of these systems.

It should be noted that various types of clusters $\left(\mathrm{CH}_{3} \mathrm{CONH}_{2}-\mathrm{CH}_{3} \mathrm{CONH}_{2}, \mathrm{Li}^{+}-\mathrm{CH}_{3} \mathrm{CONH}_{2}\right.$ and $\mathrm{Li}^{+}$ $-\mathrm{X}^{-}$) that we have analyzed in this work are binary in nature. However, one can also explore clusters that

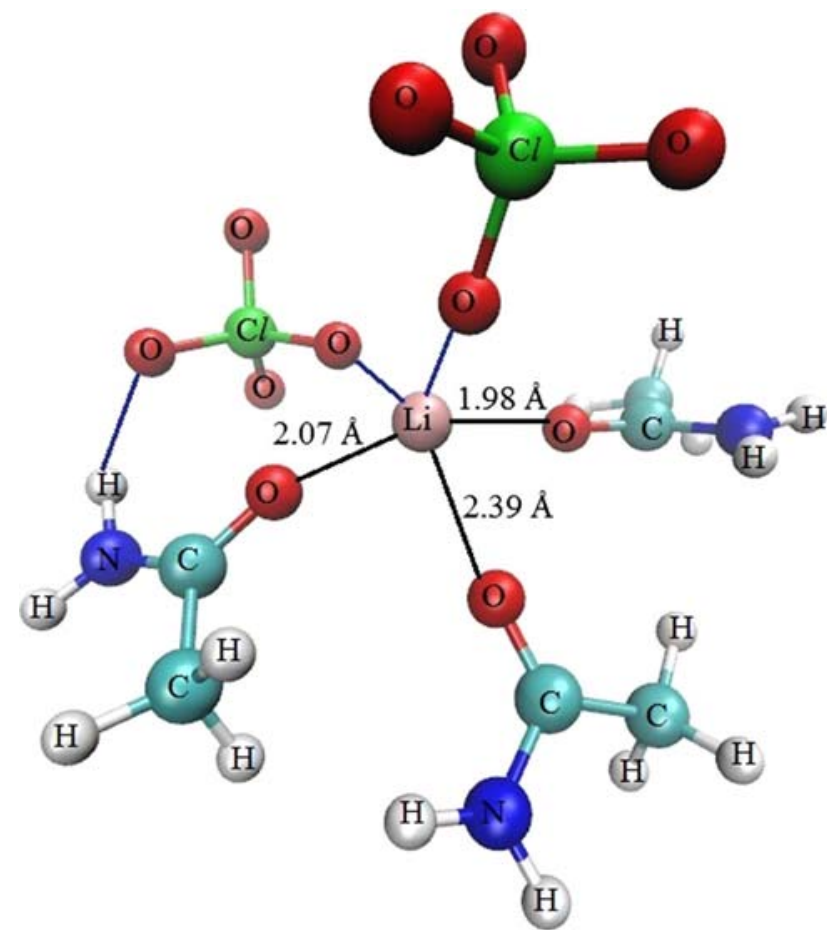

Figure 15. A six member cluster comprising of three $\mathrm{CH}_{3} \mathrm{CONH}_{2}$ molecules, one $\mathrm{Li}^{+}$and two $\mathrm{ClO}_{4}^{-}$anions are shown. These types of clusters involving all the components are formed inside the solutions. However, these are not analysed here as they do not offer any new insight.

contain all the constituents of the mixture. One such cluster is shown in Figure 15 as an example. The cluster, as shown in Figure 15 is comprised of three acetamide molecules, one lithium cation and two perchlorate anions.

\section{Conclusions}

Molecular dynamics simulations have been performed with DESs consisting of $\mathrm{CH}_{3} \mathrm{CONH}_{2}$ and lithium salts of $\mathrm{Br}^{-}, \mathrm{ClO}_{4}^{-}$and $\mathrm{NO}_{3}^{-}$at a fixed mole fraction at $303 \mathrm{~K}$ and $350 \mathrm{~K}$. Various structures formed in these ionic DESs are reflected via the simulated RDFs. Analyses of these RDFs reveal the presence of complex interspecies interactions and solution heterogeneity in all these DESs. The observed multiple peaks in the $\mathrm{Li}^{+}-\mathrm{Li}^{+} \mathrm{RDF}$ also suggests that three different kinds of ion conformations are possible for $\mathrm{ClO}_{4}^{-}$and $\mathrm{NO}_{3}^{-}$. Cluster size and lifetime distributions have also been obtained in order to generate a microscopic understanding of the local solution structure. Both size and lifetime distributions have been partitioned into three categories: $\mathrm{CH}_{3} \mathrm{CONH}_{2}-\mathrm{CH}_{3} \mathrm{CONH}_{2}, \mathrm{Li}^{+}-\mathrm{CH}_{3} \mathrm{CONH}_{2}$ and $\mathrm{Li}^{+}-\mathrm{X}^{-}$. This provides a better idea about the impact of electrolyte on solution structure. The cluster size distribution of $\mathrm{CH}_{3} \mathrm{CONH}_{2}-\mathrm{CH}_{3} \mathrm{CONH}_{2}$ 
and $\mathrm{Li}^{+}-\mathrm{CH}_{3} \mathrm{CONH}_{2}$ is found to be distinctly different from that for $\mathrm{Li}^{+}-\mathrm{X}^{-}$. The ion dependence of the cluster size is evident only in $\mathrm{Li}^{+}-\mathrm{CH}_{3} \mathrm{CONH}_{2}$ distributions. As the temperature is increased, the distribution becomes narrower but only slightly. Next, we have shown the lifetime distributions following the protocol of hydrogen bond lifetime. Here, the ion dependence is evident. $\mathrm{CH}_{3} \mathrm{CONH}_{2}-\mathrm{CH}_{3} \mathrm{CONH}_{2}$ and $\mathrm{Li}^{+}-\mathrm{CH}_{3} \mathrm{CONH}_{2}$ clusters have higher lifetimes in presence of $\mathrm{Br}^{-}$. On the other hand, $\mathrm{Li}^{+}-\mathrm{X}^{-}$clusters are found to be most stable in the presence of $\mathrm{NO}_{3}^{-}$.

Similar structural investigation can be extended to other non-ionic DESs, ${ }^{80}$ binary mixtures ${ }^{81,82}$ and ionic liquids. ${ }^{83}$ Next, it would be interesting to study the dynamic heterogeneity of these systems ${ }^{71,84}$ and its anion dependence. Although, the heterogeneity in these systems have been analysed via time-resolved fluorescence experiments, ${ }^{2,25}$ a detailed molecular length-scale study is still lacking. This could form an interesting problem in future.

\section{Supplementary Information (SI)}

Force field parameters and representations of $\mathrm{CH}_{3} \mathrm{CONH}_{2}$, $\mathrm{Li}^{+}, \mathrm{Br}^{-}, \mathrm{ClO}_{4}^{-}, \mathrm{NO}_{3}^{-}$, density comparison between experimental data (wherever available) and simulations, distance and angle probability distribution function of acetamides at $303 \mathrm{~K}$, multi-exponential fitting parameters of all the cluster lifetime distributions are provided in Supplementary Information, which is available at www.ias.ac.in/chemsci.

\section{Acknowledgements}

Mr. S. Das thanks the CSIR, India for providing research fellowship. Computational facilities provided by a TUE-CMS project at the centre (SR/NM/NS-29/2011(G)) are utilized for the work presented here.

\section{References}

1. Rogers R D and Seddon K R (Eds.) 2002 In Ionic liquids: Industrial Application for Green Chemistry (Washington, DC: ACS Symposium Series 818; American Chemical Society)

2. Wasserscheid P and Welton T (Eds.) 2003 In Ionic Liquids in Synthesis. (New York: Wiley)

3. Wagle D V, Zhao H and Baker G A 2014 Deep eutectic solvents: Sustainable media for nanoscale and functional materials Acc. Chem. Res. 472299

4. Zhang Q, De Oliveira Vigier K, Royer S and Jerome F 2012 Deep eutectic solvents: Syntheses, properties and applications Chem. Soc. Rev. $\mathbf{4 1} 7108$

5. Abbott A P, Capper G, Davies D L, Rasheed R K and Tambyrajah V 2003 Novel solvent properties of choline chloride/urea mixtures Chem. Commun. 170
6. Smith E L, Abbott A P and Ryder K S 2014 Deep eutectic solvents (DESs) and their applications Chem. Rev. 114 11060

7. Abbott A P, Capper G, Davies D L, McKenzie K J and Obi S U 2006 Solubility of metal oxides in deep eutectic solvents based on choline chloride J. Chem. Eng. Data 511280

8. Abbott A P, Cullis P M, Gibson M J, Harris R C and Raven E 2007 Extraction of glycerol from biodiesel into a eutectic based ionic liquid Green Chem. 9868

9. Abbott A P, Bell T J, Handa S and Stoddart B 2006 Cationic functionalisation of cellulose using a choline based ionic liquid analogue Green Chem. 8784

10. Zhao H and Baker G A 2013 Ionic liquids and deep eutectic solvents for biodiesel synthesis: a review J. Chem. Technol. Biotechnol. 883

11. Wasserscheid P and Keim W 2000 Ionic liquids-new "solutions" for transition metal catalysis Angew. Chem. Int. Ed. 393772

12. Cordaro J G, Rubin N C and Bradshaw R W 2011 Multicomponent molten salt mixtures based on nitrate/nitrite anions J. Sol. Energy Eng. 133011014

13. Abbott A P, Capper G, Davies D L and Rasheed R K 2004 Ionic liquid analogues formed from hydrated metal salts Chem. Eur. J. 103769

14. Abbott A P, Capper G, Davies D L and Rasheed R 2004 Ionic liquids based upon metal halide/substituted quaternary ammonium salt mixtures Inorg. Chem. $\mathbf{4 3} 3447$

15. Abbott A P, Capper G, Davies D L, Munro H L, Rasheed R K and Tambyrajah V 2001 Preparation of novel, moisture-stable, Lewis-acidic ionic liquids containing quaternary ammonium salts with functional side chains Chem. Commun. 192010

16. Sharma M, Mukesh C, Mondal D and Prasad K 2013 Dissolution of $\alpha$-chitin in deep eutectic solvents $R S C$ Adv. 318149

17. Dai Y, van Spronsen J, Witkamp G -J, Verpoorte R and Choi Y H 2013 Ionic liquid and deep eutectic solvents in natural products research: Mixtures of solids as extraction solvents J. Nat. Prod. 762162

18. Zeng Q, Wang Y, Huang Y, Ding X, Chen J and Xu K 2014 Deep eutectic solvents as novel extraction media for protein partitioning Analyst 1392565

19. van der Zwan G and Hynes J T 1983 Nonequilibrium solvation dynamics in solution reactions $J$. Chem. Phys. $\mathbf{7 8}$ 4174

20. van der Zwan G and Hynes J T 1991 Chemical reaction rates and solvation dynamics in electrolyte solutions: ion atmosphere friction Chem. Phys. 152169

21. Pradhan T and Biswas R 2007 Electrolyte-concentration and ion-size dependence of excited-state intramolecular charge-transfer reaction in (alkylamino)benzonitriles: Time-resolved fluorescence emission studies J. Phys. Chem. A 11111524

22. Guchhait B, Das S, Daschakraborty S and Biswas R 2014 Interaction and dynamics of (alkylamide + electrolyte) deep eutectics: Dependence on alkyl chain-length, temperature, and anion identity J. Chem. Phys. 140104514

23. Das A, Das S and Biswas R 2013 Fast fluctuations in deep eutectic melts: Multi-probe fluorescence measurements and all-atom molecular dynamics simulation study Chem. Phys. Lett. 58147 
24. Guchhait B, Gazi H A R, Kashyap H K and Biswas R 2010 Fluorescence spectroscopic studies of (acetamide+sodium/potassium thiocyanates) molten mixtures: Composition and temperature dependence $J$. Phys. Chem. B 1145066

25. Guchhait B, Daschakraborty S and Biswas R 2012 Medium decoupling of dynamics at temperatures $\sim 100$ $\mathrm{K}$ above glass-transition temperature: A case study with (acetamide + lithium bromide/nitrate) melts J. Chem. Phys. 136174503

26. Gazi H A R, Guchhait B, Daschakraborty S and Biswas R 2011 Fluorescence dynamics in supercooled (acetamide + calcium nitrate) molten mixtures Chem. Phys. Lett. 501 358

27. Das A and Biswas R 2015 Dynamic solvent control of a reaction in ionic deep eutectic solvents: Time-resolved fluorescence measurements of reactive and nonreactive dynamics in (choline chloride + urea) melts J. Phys. Chem. B 11910102

28. Tripathy S N, Wojnarowska Z, Knapik J, Shirota H, Biswas R and Paluch M 2015 Glass transition dynamics and conductivity scaling in ionic deep eutectic solvents: The case of (acetamide+lithium nitrate/sodium thiocyanate) melts J. Chem. Phys. 142184504

29. Mukherjee K, Das A, Choudhury S, Barman A and Biswas R 2015 Dielectric relaxations of (acetamide + electrolyte) deep eutectic solvents in the frequency window, $0.2 \leq v / \mathrm{GHz} \leq 50$ : Anion and cation dependence J. Phys. Chem. B 1198063

30. Biswas R, Das A and Shirota H 2014 Low-frequency collective dynamics in deep eutectic solvents of acetamide and electrolytes: A femtosecond Raman-induced Kerr effect spectroscopic study J. Chem. Phys. 141134506

31. Pal T and Biswas R 2011 Heterogeneity and viscosity decoupling in (acetamide + electrolyte) molten mixtures: A model simulation study Chem. Phys. Lett. 517180

32. Das S, Biswas R and Mukherjee B 2015 Reorientational jump dynamics and its connections to hydrogen bond relaxation in molten acetamide: An all-atom molecular dynamics simulation study J. Phys. Chem. B 119274

33. Das S, Biswas R and Mukherjee B 2015 Orientational jumps in (acetamide + electrolyte) deep eutectics: Anion dependence J. Phys. Chem. B 11911157

34. Das S, Biswas R and Mukherjee B 2016 Collective dynamic dipole moment and orientation fluctuations, cooperative hydrogen bond relaxations, and their connections to dielectric relaxation in ionic acetamide deep eutectics: Microscopic insight from simulations J. Chem. Phys. 145084504

35. Manthiram A 2011 Materials challenges and opportunities of lithium ion batteries J. Phys. Chem. Lett. 2176

36. Erickson E M, Ghanty C and Aurbach D 2014 New horizons for conventional lithium ion battery technology $J$. Phys. Chem. Lett. 53313

37. Nazri G A and Pistoia G (Eds.) 2004 In Lithium Batteries: Science and Technology (New York: Springer)

38. Zhang S S 2006 A review on electrolyte additives for lithium-ion batteries J. Power Sources 1621379

39. Figueiredo P H, Siqueira L J A and Ribeiro M C C 2012 The equilibrium structure of lithium salt solutions in ether-functionalized ammonium ionic liquids $J$. Phys. Chem. B 11612319
40. Niu S, Cao Z, Li S and Yan T 2010 Structure and transport properties of the $\mathrm{LiPF}_{6}$ doped 1-ethyl-2,3dimethyl-imidazolium hexafluorophosphate ionic liquids: A molecular dynamics study J. Phys. Chem. B 114 877

41. Borodin O and Smith G D 2006 LiTFSI structure and transport in ethylene carbonate from molecular dynamics simulations J. Phys. Chem. B 1104971

42. Smith W and Forster T R 1999 The DL_POLY Molecular Simulation Package (Cheshire, UK: Daresbury Laboratory)

43. Mitchell J A and Reid E E 1931 The preparation of aliphatic amides J. Am. Chem. Soc. 531879

44. MacKerell Jr A D, Wiorkiewicz-Kuczera J and Karplus M 1995 An all-atom empirical energy function for the simulation of nucleic acids J. Am. Chem. Soc. 11711946

45. Jensen K P and Jorgensen W L 2006 Halide, ammonium, and alkali metal ion parameters for modeling aqueous solutions J. Chem. Theory Comput. 21499

46. Cadena C and Maginn E J 2006 Molecular simulation study of some thermophysical and transport properties of triazolium-based ionic liquids J. Phys. Chem. B 110 18026

47. Canongia Lopes J N, Deschamps J and Padua A A H 2004 Modeling ionic liquids using a systematic all-atom force field J. Phys. Chem. B $\mathbf{1 0 8} 2038$

48. Yong C W DL_FIELD 2011 (Cheshire, U. K.: STFC Daresbury Laboratory)

49. Allen M P and Tildesley D J 1987 In Computer Simulations of Liquids (New York: Oxford University Press)

50. Martinez L, Andrade R, Birgin E G and Martinez J M 2009 PACKMOL: A package for building initial configurations for molecular dynamics simulations J. Comput. Chem. 302157

51. Nose S 1984 A unified formulation of the constant temperature molecular dynamics methods J. Chem. Phys. 81 511

52. Hoover W G 1985 Canonical dynamics: Equilibrium phase-space distributions Phys. Rev. A 311695

53. Humphrey W, Dalke A and Schulten K 1996 VMD: Visual molecular dynamics J. Mol. Graph. 1433

54. Costa L T and Ribeiro M C C 2006 Molecular dynamics simulation of polymer electrolytes based on poly(ethylene oxide) and ionic liquids. I. Structural properties J. Chem. Phys. 124184902

55. Borodin $\mathrm{O}$, Smith $\mathrm{G} \mathrm{D}$ and Henderson $\mathrm{W} 2006 \mathrm{Li}^{+}$ionic liquids J. Phys. Chem. B 11016879

56. Borodin O and Smith G D 2006 Structure and dynamics of $N$-propylpyrrolidinium bis(trifluoromethanesulfonyl)imide ionic liquid from molecular dynamics simulations J. Phys. Chem. B 110 11481

57. Li Z, Smith G D and Bedrov D $2012 \mathrm{Li}^{+}$Solvation and transport properties in ionic liquid/lithium salt mixtures: A molecular dynamics simulation study J. Phys. Chem. B 11612801

58. Triggs N E and Valentini J J 1992 An investigation of hydrogen bonding in amides using Raman spectroscopy J. Phys. Chem. 966922

59. Whitfield T W, Martyna G J, Allison S, Bates S P, Vass $\mathrm{H}$ and Crain J 2006 Structure and hydrogen bonding in neat N-methylacetamide: Classical molecular dynamics 
and raman spectroscopy studies of a liquid of peptidic fragments J. Phys. Chem. B 1103624

60. Kuduva S S, Blaser D, Boese R and Desiraju G R 2001 Crystal engineering of primary cubanecarboxamides. Repetitive formation of an unexpected $\mathrm{N}-\mathrm{H} \cdots \mathrm{O}$ hydrogen-bonded network J. Org. Chem. 661621

61. Ludwig R 2000 Cooperative hydrogen bonding in amides and peptides J. Mol. Liq. 8465.

62. Ludwig R, Weinhold F and Farrar T C 1997 Theoretical study of hydrogen bonding in liquid and gaseous N-methylformamide J. Chem. Phys. 107499

63. Etter M C 1990 Encoding and decoding hydrogen-bond patterns of organic compounds Acc. Chem. Res. 23120

64. Ottersen T 1975 On the structure of the peptide linkage. The structures of formamide and acetamide at --methylformamide Acta Chem. Scand. A 29939

65. Zobel D, Luger P, Dreissig W and Koritsanszky T 1992 Charge density studies on small organic molecules around $20 \mathrm{~K}$ : Oxalic acid dihydrate at $15 \mathrm{~K}$ and acetamide at $23 \mathrm{~K}$ Acta Crystallogr. B $\mathbf{4 8} 837$

66. Jeffrey G A, Ruble J R, McMullan R K, DeFrees D J, Binkley J S and Pople J A 1980 Neutron diffraction at 23 $\mathrm{K}$ and $a b$ initio molecular-orbital studies of the molecular structure of acetamide Acta Crystallogr. B $\mathbf{3 6} 2292$

67. Nasr S, Ghédira M and Cortés R 1999 H-bonding in liquid acetamide as studied by x-ray scattering J. Chem. Phys. 11010487

68. Nasr S $2001 \mathrm{H}$-bonding in amorphous acetamide $\mathrm{CH}_{3}$ as studied by X-ray scattering J. Chem. Phys. 1156569

69. Omta A W, Kropman M F, Woutersen S and Bakker H J 2003 Negligible effect of ions on the hydrogen-bond structure in liquid water Science $\mathbf{3 0 1} 347$

70. Bondarenko G V and Gorbaty Y E 2011 Hydrogen bonding in aqueous solution of $\mathrm{NaClO}_{4}$ Mol. Phys. 109783

71. Pal T and Biswas R 2015 Composition dependence of dynamic heterogeneity time- and length scales in $[\mathrm{Omim}]\left[\mathrm{BF}_{4}\right] /$ water binary mixtures: Molecular dynamics simulation study J. Phys. Chem. B 11915683

72. Li S, Cao Z, Peng Y, Liu L, Wang Y, Wang S, Wang J Q, Yan T, Gao X -P, Song D -Y and Shen P -W 2008 Molecular dynamics simulation of LiTFSI-acetamide electrolytes: Structural properties J. Phys. Chem. B 112 6398
73. Méndez-Morales T, Carrete J, Cabeza O, Russina O, Triolo A, Gallego L J and Varela L M 2014 Solvation of lithium salts in protic ionic liquids: A molecular dynamics study J. Phys. Chem. B $\mathbf{1 1 8} 761$

74. Méndez-Morales T, Carrete J, Bouzon-Capelo S, PerezRodriguez M, Cabeza O, Gallego L J and Varela L M 2013 MD Simulations of the formation of stable clusters in mixtures of alkaline salts and imidazolium-based ionic liquids J. Phys. Chem. B 1173207

75. Dougan L, Bates S P, Hargreaves R, Fox J P, Crain J, Finney J L, Reat V and Soper A K 2004 Methanolwater solutions: A bi-percolating liquid mixture J. Chem. Phys. 1216456.

76. Hanke C G and Lynden-Bell R M 2003 A simulation study of water-dialkylimidazolium ionic liquid mixtures J. Phys. Chem. B $\mathbf{1 0 7} 10873$

77. Rapaport D C 1983 Hydrogen bonds in water Mol. Phys. 501151

78. Chandra A 2000 Effects of ion atmosphere on hydrogenbond dynamics in aqueous electrolyte solutions Phys. Rev. Lett. 85768

79. Luzar A 2000 Resolving the hydrogen bond dynamics conundrum J. Chem. Phys. 11310663

80. Das A, Das S and Biswas R 2015 Density relaxation and particle motion characteristics in a non-ionic deep eutectic solvent (acetamide + urea): Time-resolved fluorescence measurements and all-atom molecular dynamics simulations J. Chem. Phys. 142034505

81. Indra S and Biswas R 2015 Hydrogen-bond dynamics of water in presence of an amphiphile, tetramethylurea: signature of confinement-induced effects Mol. Simul. 41 471

82. Indra S and Biswas R 2015 Heterogeneity in (2butoxyethanol + water) mixtures: Hydrophobicityinduced aggregation or criticality-driven concentration fluctuations? J. Chem. Phys. 142204501

83. Pal T and Biswas R 2013 Rank-dependent orientational relaxation in an ionic liquid: an all-atom simulation study Theor. Chem. Acc. 1321348

84. Pal T and Biswas R 2014 Slow solvation in ionic liquids: Connections to non-Gaussian moves and multi-point correlations J. Chem. Phys. 141104501 